\title{
Inulin-fortification of a processed meat product attenuates formation of nitroso compounds in the gut of healthy rats
}

Article

Accepted Version

Thøgersen, R., Gray, N., Kuhnle, G., Van Hecke, T., De Smet, S., Young, J. F., Sundekilde, U. K., Hansen, A. K. and Bertram, H. C. (2019) Inulin-fortification of a processed meat product attenuates formation of nitroso compounds in the gut of healthy rats. Food Chemistry, 302. 125339. ISSN 03088146 doi: https://doi.org/10.1016/j.foodchem.2019.125339 Available at https://centaur.reading.ac.uk/85569/

It is advisable to refer to the publisher's version if you intend to cite from the work. See Guidance on citing.

To link to this article DOI: http://dx.doi.org/10.1016/j.foodchem.2019.125339

All outputs in CentAUR are protected by Intellectual Property Rights law, including copyright law. Copyright and IPR is retained by the creators or other copyright holders. Terms and conditions for use of this material are defined in the End User Agreement. 


\section{CentAUR}

Central Archive at the University of Reading

Reading's research outputs online 
1 Inulin-fortification of a processed meat product attenuates formation of nitroso compounds in

2 the gut of healthy rats

3 Rebekka Thøgersen ${ }^{\mathrm{a}}$, Nicola Gray ${ }^{\mathrm{b}}$, Gunter Kuhnle $^{\mathrm{b}}$, Thomas Van Hecke ${ }^{\mathrm{c}}$, Stefaan De Smet ${ }^{\mathrm{c}}$, Jette

$4 \quad$ Feveile Young $^{\mathrm{a}}$, Ulrik Kræmer Sundekilde ${ }^{\mathrm{a}}$, Axel Kornerup Hansen ${ }^{\mathrm{d}}$, Hanne Christine Bertram ${ }^{\mathrm{a} *}$

$5 \quad$ a Department of Food Science, Aarhus University, Denmark

$6 \quad{ }^{\mathrm{b}}$ Department of Food \& Nutritional Sciences, University of Reading, United Kingdom

$7 \quad{ }^{\mathrm{c}}$ Department of Animal Sciences and Aquatic Ecology, Ghent University, Belgium

$8{ }^{\mathrm{d}}$ Department of Veterinary and Animal Sciences, Faculty of Health and Medical Sciences, University

9 of Copenhagen, Denmark

*Corresponding author: Prof. H. C. Bertram, Aarhus University, Kirstinebjergvej 10, 5792, Aarslev,

11 Denmark, e-mail: hannec.bertram@food.au.dk, phone: + 4587158353

\section{Abbreviations}

ATNC, apparent total N-nitroso compounds; CRC, colorectal cancer; DM, dry matter; GSH-Px, glutathione peroxidase; HEX, hexanal; MDA, malondialdehyde; NOC, N-nitroso compounds; $\mathrm{O}^{6} \mathrm{MeG}$, $\mathrm{O}^{6}$-methyl-2-deoxyguanosine; OPLS-DA, orthogonal projections to latent structures discriminant analysis; PCA, principal component analysis; PCC, protein carbonyl compounds; RSNO, nitrosothiols; FeNO, nitrosyl iron compounds; SCFA, short chain fatty acid; TSP, 3-(trimethylsilyl)-propionate; 4HNE, 4-hydroxynonenal. 


\section{Abstract}

22 Intake of red and processed meat has been suspected to increase colorectal cancer risk potentially via

23 endogenous formation of carcinogenic $N$-nitroso compounds or increased lipid- and protein oxidation.

24 Here we investigated the effect of inulin fortification of a pork sausage on these parameters. During

25 four weeks, healthy Sprague-Dawley rats $(n=30)$ were fed one of three diets; inulin-fortified pork

26 sausage, control pork sausage or a standard chow diet. Fecal content of apparent total N-nitroso

27 compounds (ATNC), nitrosothiols and nitrosyl iron compounds (FeNO) were analyzed in addition to

28 liver metabolism and oxidation products formed in liver, plasma and diets. Intriguingly, inulin

29 fortification reduced fecal ATNC $(p=0.03)$ and FeNO $(p=0.04)$ concentration. The study revealed

30 that inulin fortification of processed meat could be a strategy to reduce nitroso compounds formed

31 endogenously after consumption.

33 Key words Fiber-fortification, inulin, processed meat, nitroso compounds, oxidation 


\section{Introduction}

Consumption of red and particularly processed meat has been associated with a possible increased risk of colorectal cancer (CRC) (Chan et al., 2011). Among the major hypotheses explaining this possible association, endogenous formation of $N$-nitroso compounds (NOCs) following red or processed meat ingestion has been suggested (Hughes, Cross, Pollock and Bingham, 2001). Many NOCs are suspected to be carcinogenic and red meat consumption has been shown to dose-dependently increase the fecal excretion of NOCs (Hughes et al., 2001). NOCs can lead to alkylation of DNA, resulting in the formation of pro-mutagenic DNA adducts. This can induce $\mathrm{G}: \mathrm{C} \rightarrow \mathrm{A}: \mathrm{T}$ mutations, which might eventually initiate carcinogenesis (Gottschalg, Scott, Burns and Shuker, 2007, Mirvish, 1995). Intake of red meat has in fact been shown to increase DNA adduct formation in mice and human, including the pro-mutagenic DNA adduct $\mathrm{O}^{6}$-methyl-2-deoxyguanosine $\left(\mathrm{O}^{6} \mathrm{Meg}\right)$ (Le Leu et al., 2015, Winter et al., 2011). Heme iron, a component of red and processed meat, has been suggested to stimulate NOC formation following red or processed meat ingestion (Cross, Pollock and Bingham, 2003). Endogenous NOCs are likely formed via various routes throughout the gastrointestinal tract, including acid and bacterial catalyzed reactions, generally as a result of the reaction between nitrosating agents and nitrosable substrates (Hughes, Magee and Bingham, 2000). Acid catalyzed nitroso compound formation occurs mainly in the stomach, where nitrosating agents, such as dietary nitrite reaching the stomach, result in the formation of various nitroso compounds (Kobayashi, 2018). The acidic environment of the stomach has been found to favor the formation of nitrosothiols, which has been suggested to be the initial step in the formation of nitroso compounds in the gastrointestinal tract (Kuhnle et al., 2007). The nitrosothiols formed in the stomach might be precursors for NOCs formed 
In the small intestine, it has been suggested that heme might be nitrosylated by nitrite or the NO released from nitrosothiols, making it possible for the nitrosylated heme to act as a nitrosating agent increasing the formation of NOC (Kuhnle et al., 2007).

Bacterial catalyzed NOC formation has been found to require the presence of bacteria with nitrite and nitrate reductase enzymes activity (Calmels, Ohshima and Bartsch, 1988, Calmels, Ohshima, Henry and Bartsch, 1996). Intriguingly, a study investigating the formation of NOCs in germ free rats found that the presence of a colonic flora was necessary for NOC formation to occur (Massey, Key, Mallett and Rowland, 1988). In the large intestine, nitrosable substrates formed via protein degradation as well as nitrosating agents are available, providing a site for bacterial catalyzed NOC formation (Hughes et al., 2000).

Besides the suggested role of heme in NOC formation, heme iron in red meat has been suggested to stimulate lipid and protein oxidation (Bastide, Pierre and Corpet, 2011, Van Hecke, Vanden Bussche, Vanhaecke, Vossen, Van Camp and De Smet, 2014). In particular, lipid oxidation may result in the formation of potentially toxic end-products including malondialdehyde (MDA) and 4-hydroxynonenal (4-HNE) formed via peroxidation particularly of polyunsaturated fatty acids. Both MDA and 4-HNE have been found to be able to react with DNA to form DNA adducts, whereas 4-HNE also has shown cytotoxic effects (Bastide et al., 2011, Nair, Bartsch and Nair, 2007).

Previous investigations have indicated that dietary fiber consumption has a protective effect against CRC development (Bingham et al., 2003). In fact, earlier studies found that dietary fibers consumed in combination with red meat attenuated meat-induced DNA damage and potential harmful protein fermentation products, whereas fecal short chain fatty acids (SCFAs) concentrations were increased (Le Leu et al., 2015, Toden, Bird, Topping and Conlon, 2007, Winter et al., 2011). Moreover, fiber addition to meat products has shown a lowering effect on lipid oxidation following in vitro digestion 
81 (Hur, Lee and Lee, 2014). Thus, we recently demonstrated that inulin fortification of a pork sausage

82 product increased fecal content of SCFAs when fed to healthy rats during a 4-week intervention

83 (Thogersen et al., 2018). Based on the same experimental study, we here investigated whether the

84 incorporation of inulin into a pork sausage product also had a protective effect on the formation of

85 apparent total N-nitroso compounds (ATNC) upon consumption. Compounds-specific denitrosation

86 prior to analysis was used in order to investigate the types of nitroso compounds formed. The effect of

87 inulin fortification on protein and lipid oxidation was examined by measuring oxidation markers in

88 plasma and liver. Furthermore, as the liver is a key metabolic organ, possible hepatic metabolic

89 changes were studied using ${ }^{1} \mathrm{H}$ nuclear magnetic resonance spectroscopy.

90 


\section{Materials and methods}

92

93

94

95

96

97

\subsection{Sausage diets}

Two different sausage batches were manufactured for the study, and Table S1 shows the nutritional composition of the experimental diets. The sausages were made from a sausage emulsion of pork meat, pork backfat, which was prepared with a bowl cutter using a standard procedure for frankfurter sausages. After mincing of pork meat and backfat, the remaining ingredients provided in Supporting Information, Table S2, were added to the minced meat. For the inulin-enriched sausages, inulin was added to a fiber content approximating the content in the chow diet (5.6\% compared to $6.05 \%)$. The inulin used was Orafti® HP (Beneo-Orafti, Oreye, Belgium), a long-chain chicory inulin product containing $99.5 \%$ inulin with an average degree of polymerization of 23 ranging from 5 to 60 . Inulin fibers were added in their dry form without any pre-treatment. Casings (22/24 lamb casings) were filled with $82 \mathrm{~g}$ meat batter to reach a final weight of $75 \mathrm{~g}$ after heat treatment. After heat treatment the sausages were frozen at stored at $-18{ }^{\circ} \mathrm{C}$ until further use.

\subsection{Rat intervention and sample collection}

Thirty healthy Sprague-Dawley rats (NTac:SD) at the age of four weeks (Taconic, Ll. Skensved, Denmark) were used in this study. The rats were housed in our Association for Assessment and Accreditation of Laboratory Animal Care (AAALAC) accredited facility, and randomly housed into ten U1400 cages (Tecniplast, Buguggiate, Italy) on aspen bedding and with enrichment (Tapyei, Harjumaa, Estonia) in groups of three rats per cage following weighing and earmarking. The facility was health monitored according to FELASA guidelines (2014) revealing none of the infections listed. The rats 
112 were allowed a seven-day adaptation period during which they were fed a standard chow diet ad

113 libitum (Altromin 1324, Brogaarden, Denmark) with free access of water. After adaptation, the rats

114 were randomly divided into three groups receiving one of the following diets during an experimental

115 period of four weeks; 1$)$ Pork sausages enriched with $5.6 \%$ chicory inulin $(n=12), 2)$ Pork sausages

116 without enrichment $(n=12), 3)$ standard chow diet (Altromin 1324), $(n=6)$. Body weight, food and

117 water intake have been published elsewhere (Thogersen et al., 2018).

118 After the intervention period, fecal samples were collected and the rats were sacrificed according to

119 previously described procedures (Thogersen et al., 2018). After anesthesia by hypnorm/midazolam

120 (diluted 1:1 with sterile water prior to mixing; $0.2 \mathrm{~mL} / \mathrm{g}$ body weight), heart blood was collected

121 followed by decapitation.. Liver samples were collected by carefully removing the liver. Samples of

122 approximately $2 \times 2 \mathrm{~cm}$ were subsequently transferred to Cryotubes and snap frozen in liquid nitrogen.

123 Samples were stored at $-80{ }^{\circ} \mathrm{C}$ until analysis.

124 The study was in accordance with Directive 2010/63/EU of the European Parliament and of the

125 Council of 22 September 2010 on the protection of animals used for scientific purposes and the Danish

126 Animal Experimentation Act (LBK 474 15/05/2014). Specific approval was granted by the Animal

127 Experiments Inspectorate under the Ministry of Environment and Food in Denmark (License No 2012-

128 15-2934-00256).

129

130

\subsection{Nitroso compounds}

131 Prior to analysis, fecal samples were disrupted using a TissueLyser LT (Qiagen). Approximately 200

$132 \mathrm{mg}$ fecal sample, $500 \mu \mathrm{L} 1.0 \mathrm{~mm}$ glass beads (Sigma-Aldrich, St. Louis, MO, USA) and $1 \mathrm{~mL}$ HPLC 
grade water per $200 \mathrm{mg}$ feces were added a $2 \mathrm{~mL}$ Eppendorf Tube and sample disruption was conducted for $10 \mathrm{~min}$ oscillating at 50 1/s. The samples were centrifuged at 14,000 x g for $15 \mathrm{~min}$ at 4

${ }^{\circ} \mathrm{C}$ and the collected supernatant was stored at $-80{ }^{\circ} \mathrm{C}$ until further analysis. Nitroso compound

determination was based on a previously described method (Kuhnle et al., 2007) with modifications

using chemiluminescence detection with an Ecomedics CLD 88 Exhalyzer (Ecomedics, Dürnten,

Switzerland). A purge vessel containing $15 \mathrm{~mL}$ of a tri-iodide solution ( $2 \mathrm{~g}$ potassium iodide, $1.3 \mathrm{~g}$

iodine $40 \mathrm{~mL}$ water and $140 \mathrm{~mL}$ glacial acetic acid) and heated to $60{ }^{\circ} \mathrm{C}$ was connected via a condenser

to a wash bottle containing $1 \mathrm{M} \mathrm{NaOH}$. The wash bottle was connected to the Ecomedics CLD 88

Exhalyzer via a polypropylene filter $(0.2 \mu \mathrm{m}$, Whatman, USA). The $\mathrm{NaOH}$ wash bottle and condenser

were kept at $0{ }^{\circ} \mathrm{C}$. For mixing injected sample and transferring released $\mathrm{NO}$ to the analyzer, nitrogen

gas was bubbled through the system and the signal obtained was processed using instrument software

Chart v5.5.8 (eDAQ, Australia). Quantification was based on the injection of sodium nitrite (Sigma-

Aldrich, Steinheim, Germany) in a concentration range of 1.22-19.5 $\mu \mathrm{M}$. For the determination of

ATNC, $100 \mu \mathrm{L}$ fecal supernatant were combined with $100 \mu \mathrm{L} 0.1 \mathrm{M}$ N-ethylmaleimide (NEM) and

0.01 M diethylene triamine pentaacetic acid (DTPA) in water to chelate metal iron and preserve nitroso

thiols, and $500 \mu \mathrm{L}$ sulfamic acid solution $(50 \mathrm{~g} / \mathrm{L}$ in $1 \mathrm{M} \mathrm{HCl}$, Fisher Scientific, Loughborough, UK) to remove nitrite, vortex mixed and incubated for $2 \mathrm{~min}$. Subsequently, the solution was injected into the reaction vessel. Nitrosothiol (RSNO) determination was conducted using the procedure prior to injection for ATNC determination followed by the addition of $100 \mu \mathrm{L}$ aqueous $\mathrm{HgCl}_{2}(10 \mathrm{mM})$. After vortex mixing and 2 min of incubation, the solution was injected into the purge vessel. Likewise, nitrosyl iron compound (FeNO) determination was conducted using the procedure prior to injection for nitrosothiol determination followed by the addition of $100 \mu \mathrm{L} \mathrm{K}_{3} \mathrm{Fe}(\mathrm{CN})_{6}(10 \mathrm{mM})$. After vortex 
156 mercury(II) stable and unstable compounds was used as a measure of nitrosothiols and the difference

157 between ferricyanide stable and unstable compounds as a measure of nitrosyl iron (Kuhnle et al., 2007).

158 A possible protective effect of inulin against NOC formation was investigated under in vitro acidic 159 conditions. Bovine hemoglobin (Sigma Aldrich, St Louis, USA), hydrochloric acid and chicory inulin 160 (Beneo $\mathrm{GmbH}$, Mannheim, Germany) were mixed resulting in final concentrations of $100 \mu \mathrm{M}, 7 \mathrm{mM}$ 161 and $740 \mu \mathrm{M}$ for the three constituents, respectively. Sodium nitrite (Sigma-Aldrich, Steinheim,

162 Germany) was added in a final concentration range of $2.5-50 \mu \mathrm{M}$ for initiation of the reaction.

163 Following incubation for 15 minutes, ATCN determination in $100 \mu \mathrm{L}$ was conducted using the 164 procedure described above. Incubation of corresponding solutions without addition of inulin was used 165 as control.

\section{$2.4{ }^{1} \mathrm{H}$ nuclear magnetic resonance spectroscopy (NMR spectroscopy)}

169

170

171

172

173

174

175

176

Intact liver tissue was analyzed by ${ }^{1} \mathrm{H}$ NMR spectroscopy using high-resolution-magic-angle spinning (HR-MAS) analysis. Approximately $10 \mathrm{mg}$ of liver sample was added to $30 \mu \mathrm{L}$ HRMAS disposable inserts (Bruker BioSpin, Gmbh, Rheinstetten, Germany) containing $10 \mu \mathrm{L} \mathrm{D}_{2} \mathrm{O}$ with $0.05 \%$ 3(trimethylsilyl)-propionate (TSP) and subsequently kept at $-80{ }^{\circ} \mathrm{C}$ until analysis. ${ }^{1} \mathrm{H}$ NMR spectroscopy was conducted using a Bruker Avance III $600 \mathrm{MHz}$ spectrometer operating at a ${ }^{1} \mathrm{H}$ frequency of 600.13 MHz equipped with an HR-MAS probe (Bruker BioSpin, Rheinstetten, Germany). A one-dimensional (1D) Carr-Purcell-Meiboom-Gill (CPMG) pulse sequence with pre-saturation to suppress the water resonance was used. The following parameters were used: number of scans $(\mathrm{NS})=128$, spectral width 
$177(\mathrm{SW})=10417 \mathrm{~Hz}$, data points $(\mathrm{TD})=32768$, target temperature $=278 \mathrm{~K}$ and a spinning speed of 4200

178 Hz. Prior to Fourier transformation, the free inductions decays (FIDs) were multiplied by a line-

179 broadening function of $0.3 \mathrm{~Hz}$. The obtained spectra were baseline- and phase corrected and referenced

180 to TSP (0.0 ppm) using Topspin 3.0 (Bruker BioSpin). Data were loaded into MATLAB R2017b

181 (Mathworks Inc., Natick, USA) and spectral regions above $9.8 \mathrm{ppm}$, below $0.5 \mathrm{ppm}$ and the water

182 signal region $(4.9-5.15 \mathrm{ppm})$ were removed. Spectra were normalized to total area of the spectrum and 183 subdivided into regions of 0.01 ppm. Chenomx NMR Suite 8.13 (Chenomx Inc., Edmonton, Canada)

184 and literature (Beckonert et al., 2010) was used for metabolite assignment. The following multivariate 185 data analysis was conducted using SIMCA 15.0 (Sartorius Stedim Data Analytics AB, Umeå, Sweden).

186 Data were pareto-scaled and principal component analysis (PCA) was conducted followed by

187 construction of an orthogonal projections to latent structures discriminant analysis (OPLS-DA) model

188 using cross validation with seven segments. An OPLS-DA S-line plot was created in order to reveal 189 metabolites important for the separation between dietary treatment groups.

\subsection{In vitro digestion of experimental diets}

192 The in vitro digestions were performed in triplicate according to a previously described protocol, specific for studying oxidation processes during passage in the gastrointestinal system (Van Hecke et al., 2014). In brief, $4.5 \mathrm{~g}$ of the experimental diets were sequentially incubated at $37^{\circ} \mathrm{C}$ for 5 minutes with $6 \mathrm{~mL}$ saliva, 2 hours with $12 \mathrm{~mL}$ gastric juice, and 2 hours with $2 \mathrm{~mL}$ bicarbonate buffer $(1 \mathrm{M}, \mathrm{pH}$ 8.0), $12 \mathrm{~mL}$ duodenal juice and $6 \mathrm{~mL}$ bile juice. After completion, samples were homogenized with an ultraturrax $(9500 \mathrm{rpm})$ and aliquots were stored at $-80^{\circ} \mathrm{C}$ until analysis of lipid and protein oxidation markers. 


\subsection{Lipid- and protein oxidation}

201

202

203

204

205

206

207

208

209

210

211

212

213

214

215

216

217

218

219

220

Oxidation parameters were measured in liver, plasma, experimental diets and in vitro digests of the diets. Liver extracts were prepared by homogenizing $1 \mathrm{~g}$ of liver tissue in $10 \mathrm{~mL} 1 \%$ Triton-X-100 phosphate buffer ( $\mathrm{pH} 7 ; 50 \mathrm{mM}$ ) for 45 seconds using an ultraturrax homogenizer, followed by centrifugation ( $15 \mathrm{~min}, 15,000 \mathrm{~g}, 4^{\circ} \mathrm{C}$ ), after which the supernatant was filtered through glass wool. Supernatants were immediately analyzed for malondialdehyde (MDA) and activity of glutathione peroxidase (GSH-Px). The measurement of total (unbound and bound) MDA was based on a previously described method (Van Hecke, Ho, Goethals and De Smet, 2017) with few modifications and was based on the formation of TBARS from the reaction of MDA with 2-thiobarbituric acid (TBA). The absorbance at $532 \mathrm{~nm}$ was measured following 1-butanol extraction, and a 1,1,3,3tetramethoxypropane standard curve was used for quantification of MDA. The activity of GSH-Px in plasma and liver extracts was determined by measuring the oxidation of NADPH whereby one unit of GSH-Px activity was defined as the amount of extract needed to oxidize $1 \mu$ mol of NADPH per min at $25{ }^{\circ} \mathrm{C}$ (Hernández, Zomeño, Ariño and Blasco, 2004). Measurement of protein carbonyl compounds (PCC) was based on a previously described method (Ganhão, Morcuende and Estévez, 2010) and based on the formation of a stable 2,4 dinitrophenylhydrazone product as a result of carbonyl groups reacting with 2,4-dinitrophenylhydrazine (2,4-DNPH). Unbound reactive 4-HNE and HEX were measured in diets and in vitro digests by HPLC following their derivatization with cyclohexanedione as previously described (Van Hecke et al., 2017).

\subsection{Statistical analysis}


221 Values are given as mean \pm SEM. For determination of statistical differences between mean values of

222 the three dietary treatment groups, one-way ANOVA were performed followed by Tukey's honest 223 significant different (HSD) test when significant differences were found. For comparison of nitroso 224 compound formation between the two sausage-based diet groups as well as ATNC formation under 225 acidic conditions, two-sample t-test was conducted. For the two sausage-based diet groups, nitroso 226 compound formation below the detection limit was set to zero. P-values $<0.05$ were considered 227 significant. Pearson correlations with Bonferroni-Holm corrections and $p$-value $<0.05$ were calculated 228 to investigate possible correlations between relative abundance of fecal bacteria and NOC 229 concentrations. Statistical analyses were conducted using MATLAB R2017b (Mathworks Inc., Natick, 230 USA). 
232 In the present study, 30 healthy rats were fed three different diets; inulin-fortified pork sausage product, 233 control pork sausage product or a standard chow diet, during an intervention period of four weeks. We 234 have formerly reported metabolomics analyses of fecal and blood samples collected from the rats 235 (Thogersen et al., 2018). Here nitroso compounds excretion, the liver metabolome and lipid and protein oxidation markers were measured to examine a possible beneficial effect of inulin-fortification on these parameters. Body weight did not differ between dietary treatment groups by the end of the study

238 (Thogersen et al., 2018).

\subsection{Nitroso compounds}

241 For all of the measured nitroso compounds, i.e. ATNC, nitroso thiols and nitrosyl haem, the fecal concentration was below the detection limit following chow diet consumption. In general, the highest concentrations were observed upon consumption of the control sausage. The concentration of ATNC was found to be significantly reduced after consumption of inulin-fortified sausage $(1.39 \pm 0.15 \mu \mathrm{M})$ compared to the control sausage diet $(2.13 \pm 0.28 \mu \mathrm{M})(\mathrm{p}=0.03)$ (Figure 1). Selective denitrosation prior to analysis revealed no significant difference in RSNO $(\mathrm{p}=0.11)$ or other unspecified nitroso compounds $(\mathrm{p}=0.29)$ after consumption of the two sausage-based diets. A significant reduction in FeNO $(p=0.04)$ was found after consumption of the inulin-fortified sausage $(0.79 \pm 0.06 \mu \mathrm{M})$ compared to control $(1.29 \pm 0.22 \mu \mathrm{M})$. Concentrations for each individual rat can be found in supplementary material (Table S3). A complementary experiment with incubation of bovine hemoglobin and sodium nitrite under acidic conditions with or with the addition of inulin showed no 
252 effect of inulin on ATCN formation (Table 1). Calculations of Pearson correlation coefficients with

253 Bonferroni-Holm correction and significance level $\mathrm{p}<0.05$ found no positive correlations between

254 relative abundance of gut bacteria (published elsewhere (Thogersen et al., 2018)) and concentration of

255 nitroso compounds (data not shown).

\subsection{Lipid- and protein oxidation}

259 Oxidation analyses of the experimental diets revealed that the chow diet contained higher concentrations of MDA, 4-HNE and HEX compared to the two sausage-based diets, and protein oxidation was increasing in the order control sausages, inulin-enriched sausages and chow diet (Table 2). Analysis of in vitro digests of experimental diets revealed higher MDA, 4-HNE, HEX and PCC concentrations in in vitro digests of the chow diet compared to the two sausages-based diets. Analyses of the anti-oxidative enzyme system of rat samples revealed higher GSH-Px activity in liver samples from rats fed the two sausage-based diets compared to chow diet $(\mathrm{p}<0.001)$, whereas a nearsignificant $(\mathrm{p}=0.069)$ increased GSH-Px activity was observed in plasma samples from rats fed the sausage-based diets compared to standard chow diet (Table 2).

\subsection{Liver metabolome}

PCA scores plot of spectral data obtained from HRMAS analysis of liver tissue revealed a clear

271 grouping of the rats receiving the standard chow diet in the first component explaining $74.3 \%$ of the 272 variation (Figure 2). No clear separation between the two sausage-based diets could be observed. An 
273 OPLS-DA model comparing rats fed the standard chow diet and rats fed the two sausage-based diets

274 was constructed $\left(Q^{2}=0.79\right)$ (Figure S1, Supplementary material) and S-line plot revealed that glucose 275 and lipids were among the main drivers of the separation (Figure 3). Chow diet consumption was

276 characterized by higher hepatic glucose levels, whereas consumption of the sausage-based diets was

277 characterized by higher lipid levels in the liver (Figure 3). In addition, a peak at 3.26 ppm appeared

278 important for the separation between the chow diet group and the rats fed the sausage-based diets. The $2793.26 \mathrm{ppm}$ peak is most likely arising from betaine and has its highest intensity in the chow diet group. 280 Multivariate data analysis did not show any separation between the two sausage-based diets. 


\section{Discussion}

282

283

284

285

286

287

288

289

290

291

292

293

294

295

296

297

298

299

300

301

302

\subsection{Inulin fortification reduces fecal nitroso compound excretion}

Red and processed meat intake has been suspected to cause harmful effects on colon health (Chan et al., 2011), whereas dietary fiber consumption has been associated with colonic health benefits (Bingham et al., 2003). Therefore, the inclusion of dietary fibers into processed meat products might be a strategic tool in reducing the potential meat-associated harmful effects on colon homeostasis. We have previously shown that inulin fortification of a pork sausage product positively affected the metabolome and gut microbiota of healthy rats by increasing the fecal concentration of SCFAs as well as the relative abundance of Bifidobacteria compared to a corresponding non-enriched sausage (Thogersen et al., 2018). Here we examined the effect of the same inulin fortification of a pork sausage product on the formation of nitroso compounds, the liver metabolome as well as markers of lipid and protein oxidation using a rat model.

Intriguingly, our study demonstrated that inulin fortification reduced the fecal concentration of ATNC compared to the consumption of control sausages without fortification. Compound-specific denitrosation indicated that this was partly ascribed to a reduction in nitrosyl iron compounds. Based on in vitro studies, it has previously been proposed that fermentation of non-digestible carbohydrates could lead to a reduced availability of NOC precursors in the form of amines (Allison and Macfarlane, 1989, Silvester, Bingham, Pollock, Cummings and O'Neill, 1997). In addition, under simulated gastric conditions, wheat bran has been demonstrated to act as a nitrite scavenger (Møller, Dahl and Bøckman, 1988). However, human studies investigating the effect of consuming resistant starch or wheat bran in combination with red meat showed no effect on fecal NOC excretion (Bingham et al., 1996, Silvester et al., 1997). NOC can be formed from the reaction of nitrosating agents and nitrosable substrates such as 
amines formed via fermentation of protein residues reaching the colon (Kobayashi, 2018). This

reaction can be catalyzed by colonic bacteria with nitrate- or nitrite reductase enzyme activity (Calmels et al., 1988, Calmels et al., 1996). Hence, the reducing effect that inulin fortification exerts on fecal nitroso compound excretion may be ascribed to a reduction in substrate availability or changes in catalysis of the reaction. Increasing the availability of fermentable carbohydrates in the colon upon high red meat intake might attenuate the formation of protein fermentation products by switching the bacterial fermentation of proteins towards carbohydrate fermentation (Toden et al., 2007, Winter et al., 2011), thereby reducing the availability of substrates for nitroso compound formation. The reducing effect of inulin on ATNC formation might be a result of a high colonic fermentability of inulin compared to other fermentable carbohydrates previously examined in human studies (Bingham et al., 1996, Silvester et al., 1997). We previously demonstrated a strong effect of diet on the gut microbial composition of the rats included in the present study (Thogersen et al., 2018). Hence, the reduced ATNC excretion observed after inulin-fortified sausage consumption may also be associated with changes in abundance of colonic bacteria with nitrate- or nitrite reducing activity. Alternatively, it may be caused by a reduced nitrate reductase activity, as earlier studies have shown a reducing effect of wheat bran and cellulose on this enzyme activity (Mallett, Rowland and Bearne, 1986, Mallett, Wise and Rowland, 1983). The fact that no suppressing effect of inulin on ATNC formation was found after incubation of bovine hemoglobin under in vitro acidic conditions suggests that the presence of inulin did not affect an acid-catalyzed ATNC formation expected to take place in the stomach. Thus, the reducing effect of inulin on ATNC formation appears to result from mechanisms taking place further down the gastrointestinal system. 
324 In the literature, the carcinogenicity of the different types of nitroso compounds has been discussed.

325 Hogg 2007 argued that S-nitrosothiols and nitrosyl iron species, in contrast to N-nitroso species, are not

326 tumorogenic and even suggested a possible protective effect of S-nitrosothiol and nitrosyl iron

327 formation, reducing the formation of DNA adduct alkylating agents and increasing excretion (Hogg,

328 2007). However, others argue that both nitrosothiols and nitrosyl heme may promote the formation of

329 nitroso-compound-specific DNA-adducts (Kuhnle et al., 2007) and in vitro studies have shown the

330 ability of nitrosyl heme and nitrosothiols to act as a nitrosating agents (Alkaabi, Williams, Bonnett and

331 Ooi, 1982, Bonnett, Charalambides, Martin, Sales and Fitzsimmons, 1975).

332 Fecal concentration of all of the measured nitroso compounds for rats fed the standard chow diet were

333 below the detection limit. The lower fecal concentration of nitroso compounds after chow diet

334 consumption compared to the two sausage-based diets is in accordance with earlier findings showing

335 lower fecal concentrations of nitroso compounds after consumption of a vegetarian diet compared to

336 high red meat diet (Kuhnle et al., 2007). This is likely caused by an expected higher heme iron content

337 in the sausage based diets compared to the chow diet (Cross et al., 2003) and the addition of sodium

338 nitrite salt to the sausages.

\subsection{Effect of diet on liver metabolome and oxidation products}

341 Liver metabolism is crucial to the organism, making it a key metabolic organ. HRMAS analysis of 342 intact liver tissue revealed a clear separation of the chow diet group from the two sausage-based diet 343 groups when multivariate data analysis of ${ }^{1} \mathrm{H}$ NMR spectral data was conducted. Liver tissue from rats 344 fed the sausage-based diets was characterized by higher amounts of lipids, whereas the chow diet group 
was characterized by higher hepatic glucose levels. This finding can likely be ascribed to the higher

dietary fat and carbohydrate intake for the sausage-based diet groups and chow diet group, respectively.

The results are consistent with earlier findings that the liver metabolome is influenced by metabolic

status and can be modified by diet, revealing increased hepatic glucose and lipid content after consumption of high-carbohydrate or high-fat diet, respectively (Bertram, Larsen, Chen and Jeppesen, 2012).

No effect of inulin fortification of the pork sausage product was found on lipid and protein oxidation end products in plasma or liver samples nor in in vitro digests of experimental diets. Previous studies found a lowering effect of fiber addition to meat products on lipid oxidation after in vitro digestion, probably explained by a lowering effect of fibers on lipid digestion (Hur et al., 2014, Hur, Lim, Park and Joo, 2009). In addition, Toden et al., 2010 found a reducing effect of high amylose maize starch (HAMS) on plasma MDA concentrations in plasma samples of rats fed chicken or beef with or without HAMS (Toden, Belobrajdic, Bird, Topping and Conlon, 2010). Differences in physicochemical properties characterizing different dietary fibers might affect the ability of a specific fiber to reduce lipid digestion in meats in addition to differences in lipid content and lipid size of the meat as suggested by Hur et al. 2009 (Hur et al., 2009).

Intriguingly, oxidation analysis of the experimental diets and in vitro digests of diets revealed higher concentrations of oxidation products in the chow diets compared to the two sausage-based diets. It has previously been shown that nitrite curing of pork meat reduced the formation of oxidation products compared to corresponding uncured meat after in vitro digestion (Van Hecke et al., 2014), which could explain why the two sausage-based diets show lower oxidation compared to the chow diet. The higher oxidation products in chow diet and in vitro digests of the chow diet could also be caused by a higher 
367 content of reducing sugars in the chow diet, since reducing sugars might to be able to accelerate

368 oxidation (Yamauchi, Goto, Kato and Ueno, 1984). The dry characteristics of the chow diet as well as a

369 longer storage time and higher storage temperature of the chow diet compared to the sausage-based diet

370 might also contribute to the observed increased oxidation (Lin, Hsieh and Huff, 1998).

371 The analysis of oxidation products of experimental diets and in vitro digests of diets were conducted on

372 equal amounts of fresh matter. However, the dry matter content of the chow diet is lower than that of

373 the sausage-based diets being $89 \%, 43 \%$ and $42 \%$ for chow diet, inulin-enriched sausage and control

374 sausage, respectively. Therefore, lipid oxidation products per gram dry matter of experimental diets

375 were calculated and are given in supplementary material, Table S4. According to the calculations, 4-

376 HNE and HEX were still significantly higher in the chow diet, but for MDA, the calculations showed

377 the highest concentration in the inulin-fortified sausages.

378 The higher degree of oxidation in the chow diet compared to the sausage-based diets prior to ingestion 379 was not reflected in plasma or liver samples of the rats, where no differences in oxidation products

380 between diets groups were found. Intriguingly, despite the chow diet being more oxidized prior to 381 ingestion, an increased GSH-Px activity was observed in liver as well as a near-significant increase in 382 plasma from rats fed the sausage-based diets compared to the chow diet. A high GSH-Px activity can

383 be an indication of a higher level of oxidative stress, since GSH-Px reduces lipid hydroperoxides

384 formed via oxidation of unsaturated fatty acids, thereby functioning as a defense mechanism against the

385 formation of toxic oxidation end-products (Bastide et al., 2011). Thus, the higher fat content, including 386 polyunsaturated fatty acids, in the sausage-based diets could potentially give a higher oxidative stress 387 during digestion compared to that of the chow diet resulting in increased GSH-Px activity. 
388 In conclusion, inulin fortification of a pork sausage product reduced fecal content of ATNC and FeNO 389 compared to a non-enriched sausage in healthy rats, indicating a protective effect of inulin against 390 nitroso compound formation. Although no effect of fiber fortification was found on oxidation products, 391 our results indicate a potential of using inulin fortification of processed meat products as an approach to 392 reduce the formation of potentially carcinogenic nitroso compounds. 


\section{Funding and acknowledgements}

396 The study was part of R.T's Ph.D. project and financially supported by Aarhus University and through

397 H.C.B's Eliteforsk grant (\# 6161-00016B). The authors thank Beneo GmbH for providing inulin for the 398 sausage manufacturing. The authors thank Helene Farlov and Mette Nelander for taking care of the 399 rats.

400

401 Conflict of interest

402 The authors declare no conflict of interest.

403 


\section{References}

Alkaabi S. S., Williams D. L. H., Bonnett R., Ooi S. L. A KINETIC INVESTIGATION OF THE THIONITRITE FROM (+/-)2-ACETYLAMINO-2-CARBOXY-1,1-DIMETHYLETHANETHIOL AS A POSSIBLE NITROSATING AGENT. J Chem SocPerkin Trans 2. 1982(2):227-30.

Allison C., Macfarlane G. T. Influence of $\mathrm{pH}$, nutrient availability, and growth rate on amine production by Bacteroides fragilis and Clostridium perfringens. Applied and Environmental Microbiology. 1989;55(11):2894-8.

Bastide N. M., Pierre F. H. F., Corpet D. E. Heme Iron from Meat and Risk of Colorectal Cancer: A Meta-analysis and a Review of the Mechanisms Involved. Cancer Prev Res. 2011;4(2):177-84.

Beckonert O., Coen M., Keun H. C., Wang Y., Ebbels T. M., Holmes E., Lindon J. C., Nicholson J. K. Highresolution magic-angle-spinning NMR spectroscopy for metabolic profiling of intact tissues. Nature protocols. 2010;5(6):1019-32.

Bertram H. C., Larsen L. B., Chen X., Jeppesen P. B. Impact of high-fat and high-carbohydrate diets on liver metabolism studied in a rat model with a systems biology approach. Journal of agricultural and food chemistry. 2012;60(2):676-84.

Bingham S. A., Day N. E., Luben R., Ferrari P., Slimani N., Norat T., Clavel-Chapelon F., Kesse E., Nieters A., Boeing H., Tjonneland A., Overvad K., Martinez C., Dorronsoro M., Gonzalez C. A., Key T. J., Trichopoulou A., Naska A., Vineis P., Tumino R., Krogh V., Bueno-de-Mesquita H. B., Peeters P. H., Berglund G., Hallmans G., Lund E., Skeie G., Kaaks R., Riboli E. Dietary fibre in food and protection against colorectal cancer in the European Prospective Investigation into Cancer and Nutrition (EPIC): an observational study. Lancet (London, England). 2003;361(9368):1496-501.

Bingham S. A., Pignatelli B., Pollock J. R., Ellul A., Malaveille C., Gross G., Runswick S., Cummings J. H., O'Neill I. $\mathrm{K}$. Does increased endogenous formation of $\mathrm{N}$-nitroso compounds in the human colon explain the association between red meat and colon cancer? Carcinogenesis. 1996;17(3):515-23.

Bonnett R., Charalambides A. A., Martin R. A., Sales K. D., Fitzsimmons B. W. Reactions of nitrous acid and nitric oxide with porphyrins and haems. Nitrosylhaems as nitrosating agents. Journal of the Chemical Society, Chemical Communications. 1975(21):884-5.

Calmels S., Ohshima H., Bartsch H. Nitrosamine formation by denitrifying and non-denitrifying bacteria: implication of nitrite reductase and nitrate reductase in nitrosation catalysis. Journal of general microbiology. 1988;134(1):221-6. 
Calmels S., Ohshima H., Henry Y., Bartsch H. Characterization of bacterial cytochrome cd(1)-nitrite reductase as one enzyme responsible for catalysis of nitrosation of secondary amines. Carcinogenesis. 1996;17(3):533-6.

Chan D. S., Lau R., Aune D., Vieira R., Greenwood D. C., Kampman E., Norat T. Red and processed meat and colorectal cancer incidence: meta-analysis of prospective studies. PLoS One. 2011;6(6):e20456.

Cross A. J., Pollock J. R., Bingham S. A. Haem, not protein or inorganic iron, is responsible for endogenous intestinal N-nitrosation arising from red meat. Cancer research. 2003;63(10):2358-60.

Ganhão R., Morcuende D., Estévez M. Protein oxidation in emulsified cooked burger patties with added fruit extracts: Influence on colour and texture deterioration during chill storage. Meat Science. 2010;85(3):402-9.

Gottschalg E., Scott G. B., Burns P. A., Shuker D. E. Potassium diazoacetate-induced p53 mutations in vitro in relation to formation of O6-carboxymethyl- and 06-methyl-2'-deoxyguanosine DNA adducts: relevance for gastrointestinal cancer. Carcinogenesis. 2007;28(2):356-62.

Hernández P., Zomeño L., Ariño B., Blasco A. Antioxidant, lipolytic and proteolytic enzyme activities in pork meat from different genotypes. Meat Science. 2004;66(3):525-9.

Hogg N. Red meat and colon cancer: Heme proteins and nitrite in the gut. A commentary on "Diet-induced endogenous formation of nitroso compounds in the GI tract". Free Radical Biology and Medicine. 2007;43(7):1037-9.

Hughes R., Cross A. J., Pollock J. R. A., Bingham S. Dose-dependent effect of dietary meat on endogenous colonic N-nitrosation. Carcinogenesis. 2001;22(1):199-202.

Hughes R., Magee E. A., Bingham S. Protein degradation in the large intestine: relevance to colorectal cancer. Current issues in intestinal microbiology. 2000;1(2):51-8.

Hur S. J., Lee S. Y., Lee S. J. Effect of biopolymer encapsulation on the digestibility of lipid and cholesterol oxidation products in beef during in vitro human digestion. Food chemistry. 2014;166:254-60.

Hur S. J., Lim B. O., Park G. B., Joo S. T. Effects of various fiber additions on lipid digestion during in vitro digestion of beef patties. Journal of food science. 2009;74(9):C653-7.

Kobayashi J. Effect of diet and gut environment on the gastrointestinal formation of N-nitroso compounds: A review. Nitric oxide : biology and chemistry. 2018;73:66-73. 
Kuhnle G. G., Bingham S. A. Dietary meat, endogenous nitrosation and colorectal cancer. Biochemical Society transactions. 2007;35(Pt 5):1355-7.

Kuhnle G. G., Story G. W., Reda T., Mani A. R., Moore K. P., Lunn J. C., Bingham S. A. Diet-induced endogenous formation of nitroso compounds in the GI tract. Free radical biology \& medicine. 2007;43(7):1040-7.

Le Leu R. K., Winter J. M., Christophersen C. T., Young G. P., Humphreys K. J., Hu Y., Gratz S. W., Miller R. B., Topping D. L., Bird A. R., Conlon M. A. Butyrylated starch intake can prevent red meat-induced O6-methyl-2deoxyguanosine adducts in human rectal tissue: a randomised clinical trial. The British journal of nutrition. $2015 ; 114(2): 220-30$.

Lin S., Hsieh F., Huff H. E. Effects of lipids and processing conditions on lipid oxidation of extruded dry pet food during storage. Animal Feed Science and Technology. 1998;71(3):283-94.

Mallett A. K., Rowland I. R., Bearne C. A. Influence of wheat bran on some reductive and hydrolytic activities of the rat cecal flora. Nutrition and cancer. 1986;8(2):125-31.

Mallett A. K., Wise A., Rowland I. R. Effect of dietary cellulose on the metabolic activity of the rat caecal microflora. Archives of toxicology. 1983;52(4):311-7.

Massey R. C., Key P. E., Mallett A. K., Rowland I. R. An investigation of the endogenous formation of apparent total N-nitroso compounds in conventional microflora and germ-free rats. Food and Chemical Toxicology. 1988;26(7):595-600.

Mirvish S. S. Role of N-nitroso compounds (NOC) and N-nitrosation in etiology of gastric, esophageal, nasopharyngeal and bladder cancer and contribution to cancer of known exposures to NOC. Cancer Letters. 1995;93(1):17-48.

Møller M. E., Dahl R., Bøckman O. C. A possible role of the dietary fibre product, wheat bran, as a nitrite scavenger. Food and Chemical Toxicology. 1988;26(10):841-5.

Nair U., Bartsch H., Nair J. Lipid peroxidation-induced DNA damage in cancer-prone inflammatory diseases: A review of published adduct types and levels in humans. Free Radical Biology and Medicine. 2007;43(8):1109-20.

Silvester K. R., Bingham S. A., Pollock J. R., Cummings J. H., O'Neill I. K. Effect of meat and resistant starch on fecal excretion of apparent $\mathrm{N}$-nitroso compounds and ammonia from the human large bowel. Nutrition and cancer. 1997;29(1):13-23. 
Thogersen R., Castro-Mejia J. L., Sundekilde U. K., Hansen L. H., Hansen A. K., Nielsen D. S., Bertram H. C. Ingestion of an Inulin-Enriched Pork Sausage Product Positively Modulates the Gut Microbiome and Metabolome of Healthy Rats. Molecular nutrition \& food research. 2018:e1800608.

Toden S., Belobrajdic D. P., Bird A. R., Topping D. L., Conlon M. A. Effects of dietary beef and chicken with and without high amylose maize starch on blood malondialdehyde, interleukins, IGF-I, insulin, leptin, MMP-2, and TIMP-2 concentrations in rats. Nutrition and cancer. 2010;62(4):454-65.

Toden S., Bird A. R., Topping D. L., Conlon M. A. High red meat diets induce greater numbers of colonic DNA double-strand breaks than white meat in rats: attenuation by high-amylose maize starch. Carcinogenesis. 2007;28(11):2355-62.

530

Van Hecke T., Ho P. L., Goethals S., De Smet S. The potential of herbs and spices to reduce lipid oxidation during heating and gastrointestinal digestion of a beef product. Food research international (Ottawa, Ont).

533 2017;102:785-92.

Van Hecke T., Vanden Bussche J., Vanhaecke L., Vossen E., Van Camp J., De Smet S. Nitrite curing of chicken, 536 pork, and beef inhibits oxidation but does not affect N-nitroso compound (NOC)-specific DNA adduct formation during in vitro digestion. Journal of agricultural and food chemistry. 2014;62(8):1980-8. resistant starch of red meat-induced promutagenic adducts in mouse colon. Cancer prevention research (Philadelphia, Pa). 2011;4(11):1920-8.

542

543 Yamauchi R., Goto Y., Kato K., Ueno Y. Prooxidant Effect of Dihydroxyacetone and Reducing Sugars on the 544 Autoxidation of Methyl Linoleate in Emulsions. Agricultural and Biological Chemistry. 1984;48(4):843-8. 
547 Figure 1. Concentration of fecal nitroso compounds after 4 weeks of intervention in rats, mean \pm SEM

548 (Chow, $n=6$; Sausage + inulin, $n=12$; control sausage, $n=12$ ). Different letters within each

549 compound class indicate significant differences between control sausage and inulin sausage. ATNC,

550 apparent total N-nitroso compounds; RSNO, nitrosothiols; FeNO, nitrosyl iron compounds; other,

551 remaining unspecified nitroso compounds. Concentrations for each individual rat can be found in

552 supplementary material (Table S3). For the chow diet group, all nitroso compounds analyzed were

553 below the detection limit.

554

555

556 Figure 2. PCA scores plot of NMR metabolite profiles obtained for liver samples from rats fed inulin-

557 enriched sausages (yellow), control sausages (red) or chow diet (blue) for 4 weeks.

558

559 Figure 3. OPLS-DA S-line plot of liver samples from rats fed either of the two sausage-based diets $(n=$ $56024)$ versus standard chow diet for 4 weeks $(n=6), Q^{2}=0.79$.

561

562

563

564 


\begin{tabular}{cccc}
\hline $\begin{array}{c}\text { NaNO}_{2} \\
\text { concentration }(\boldsymbol{\mu M})\end{array}$ & Control (AUC) & + inulin (AUC) & p-value \\
\hline 50 & $240.33 \pm 6.35$ & $229.54 \pm 1.21$ & 0.28 \\
\hline 40 & $179.56 \pm 2.69$ & $167.91 \pm 5.18$ & 0.12 \\
\hline 30 & $88.52 \pm 9.39$ & $104.88 \pm 9.42$ & 0.29 \\
\hline 20 & $60.86 \pm 2.11$ & $60.87 \pm 0.58$ & 1.00 \\
\hline 10 & $20.47 \pm 1.10$ & $21.60 \pm 0.75$ & 0.44 \\
\hline 5 & $8.25 \pm 0.48$ & $8.01 \pm 1.27$ & 0.87 \\
\hline 2.5 & $3.58 \pm 0.29$ & $3.30 \pm 0.55$ & 0.67
\end{tabular}

565

Table 1. ATNC formation expressed as area under the curve (AUC) (mean $\pm S E M, n=3$ ) for incubation of bovine hemoglobin and varying

566

amounts of sodium nitrite under acidic conditions with or without (control) the addition of inulin.

567

568 


\begin{tabular}{|c|c|c|c|c|c|}
\hline & & Chow & $\begin{array}{c}\text { Sausage + } \\
\text { inulin }\end{array}$ & $\begin{array}{l}\text { Control } \\
\text { sausage }\end{array}$ & $\begin{array}{c}\text { p- } \\
\text { value }\end{array}$ \\
\hline \multirow{3}{*}{ Liver } & MDA (nmol/g liver) & $419.70 \pm 15.09$ & $395.61 \pm 9.52$ & $399.09 \pm 8.60$ & 0.33 \\
\hline & GSH-Px (U/g) & $51.3 \pm 2.7^{\mathrm{a}}$ & $73.5 \pm 1.7^{b}$ & $77.6 \pm 2.9^{b}$ & $<0.001$ \\
\hline & PCC (nmol DNPH/mg protein) & $4.41 \pm 0.19$ & $4.28 \pm 0.23$ & $4.83 \pm 0.33$ & 0.31 \\
\hline \multirow{2}{*}{ Plasma } & $\operatorname{MDA}(\mathrm{nmol} / \mathrm{mL})$ & $9.51 \pm 0.61$ & $9.83 \pm 0.30$ & $9.83 \pm 0.21$ & 0.81 \\
\hline & GSH-Px (U/mL) & $1.96 \pm 0.01$ & $2.32 \pm 0.15$ & $2.41 \pm 0.08$ & 0.07 \\
\hline \multirow{4}{*}{ Diets } & MDA (nmol/g diet) & $65.5 \pm 4.2^{\mathrm{a}}$ & $39.4 \pm 0.35^{b}$ & $32.0 \pm 1.0^{\mathrm{b}}$ & $<0.001$ \\
\hline & 4-HNE (ng/g diet) & $64.1 \pm 7.5^{\mathrm{a}}$ & $4.2 \pm 0.91^{b}$ & $3.7 \pm 0 .^{b}$ & $<0.001$ \\
\hline & HEX (ng/g diet) & $508.9 \pm 26.1^{\mathrm{a}}$ & $7.4 \pm 0.2^{b}$ & $8.4 \pm 2.1^{b}$ & $<0.001$ \\
\hline & PCC (nmol DNPH/mg protein) & $13.6 \pm 0.5^{\mathrm{a}}$ & $9.5 \pm 0.5^{c}$ & $7.4 \pm 0.2^{b}$ & $<0.001$ \\
\hline \multirow{4}{*}{$\begin{array}{l}\text { In vitro } \\
\text { digest }\end{array}$} & MDA (nmol/g digest) & $76.4 \pm 4.0^{\mathrm{a}}$ & $25.8 \pm 0.9^{b}$ & $24.1 \pm 0.2^{b}$ & $<0.001$ \\
\hline & 4-HNE (ng/g digest) & $20.4 \pm 0.9^{\mathrm{a}}$ & $3.4 \pm 0.3^{\mathrm{b}}$ & $4.2 \pm 0.1^{\mathrm{b}}$ & $<0.001$ \\
\hline & HEX (ng/g digest) & $87.4 \pm 1.0^{\mathrm{a}}$ & $6.4 \pm 0.4^{b}$ & $7.4 \pm 0.5^{b}$ & $<0.001$ \\
\hline & PCC (nmol DNPH/mg protein) & $13.7 \pm 0.2^{\mathrm{a}}$ & $8.3 \pm 0.2^{b}$ & $8.0 \pm 0.4^{b}$ & $<0.001$ \\
\hline
\end{tabular}

570

571

572

573

574

575

576

Table 2. Determination of oxidation parameters of rat liver, plasma, experimental diets and in vitro digestion of experimental diets,

mean \pm SEM (For liver and plasma: chow, $n=6$; Sausage + inulin, $n=12$; control sausage, $n=12$, except for MDA in plasma: chow, $n=4$; Sausage + inulin, $n=10$; control sausage, $n=10$ and PCC in liver: chow, $n=6$; Sausage + inulin, $n=12 ;$ control sausage, $n=10$. For diets and in vitro digest, $n=3$ for each diet group). MDA, malondialdehyde; GSH-Px, Glutathione peroxidase; 4-HNE, 4-hydroxy-2-neonenal; HEX, hexanal; PCC, protein carbonyl compounds. 


\section{Declaration of interests}

$\bigotimes$ The authors declare that they have no known competing financial interests or personal relationships that could have appeared to influence the work reported in this paper.

$\square$ The authors declare the following financial interests/personal relationships which may be considered as potential competing interests:

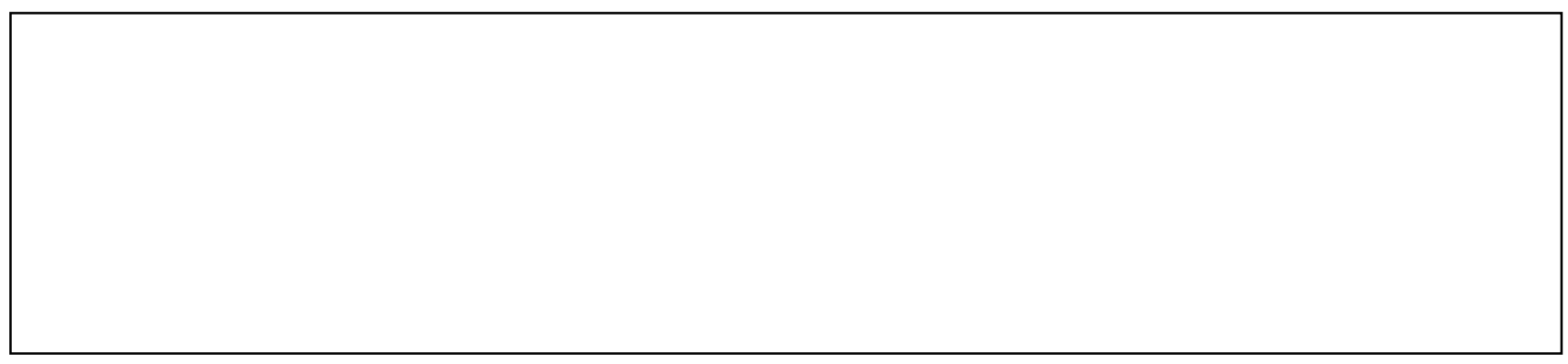


Figure 1

Click here to download Figure(s): Fig 1.docx

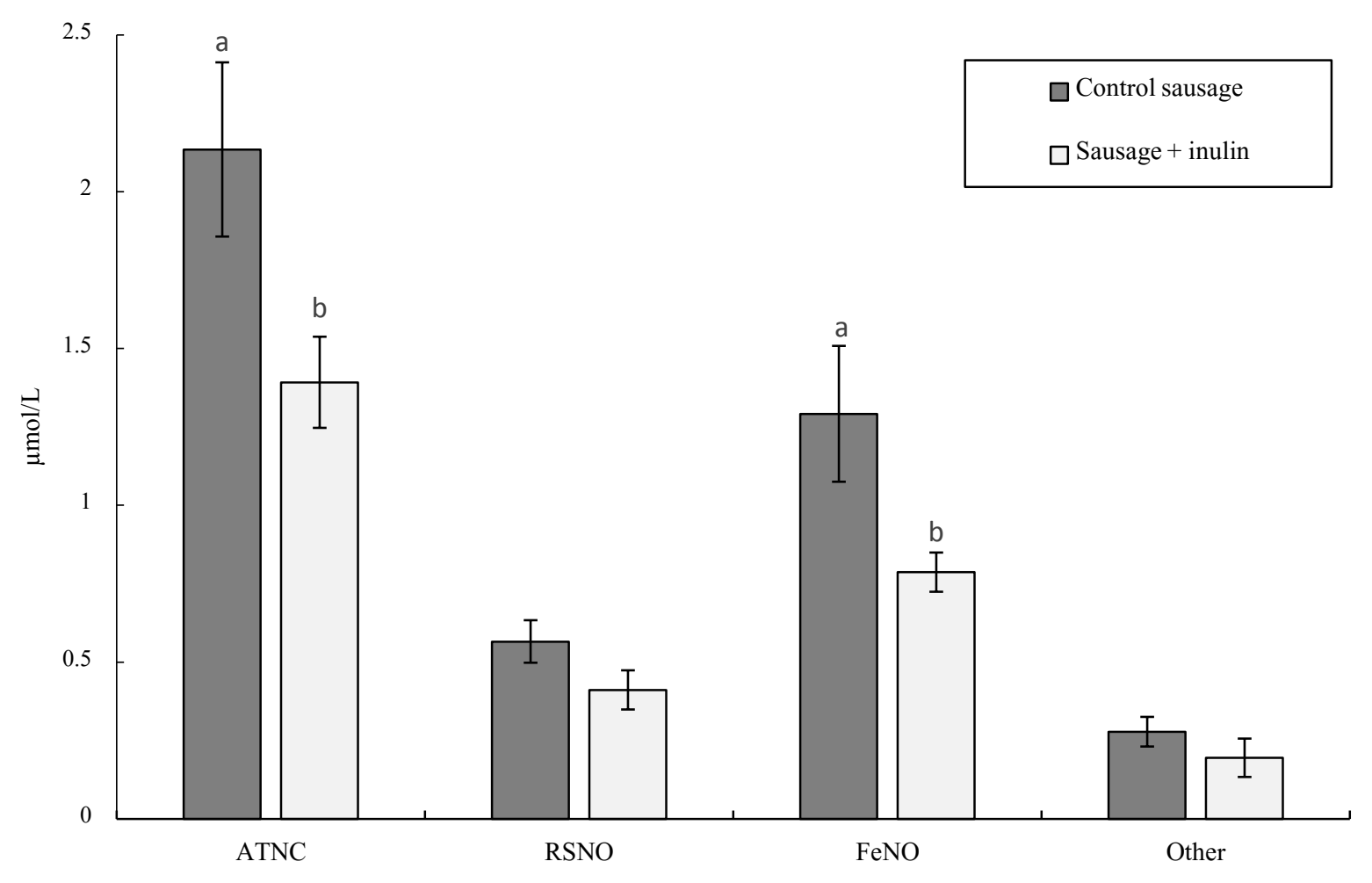


Figure 2

Click here to download Figure(s): Fig 2.docx

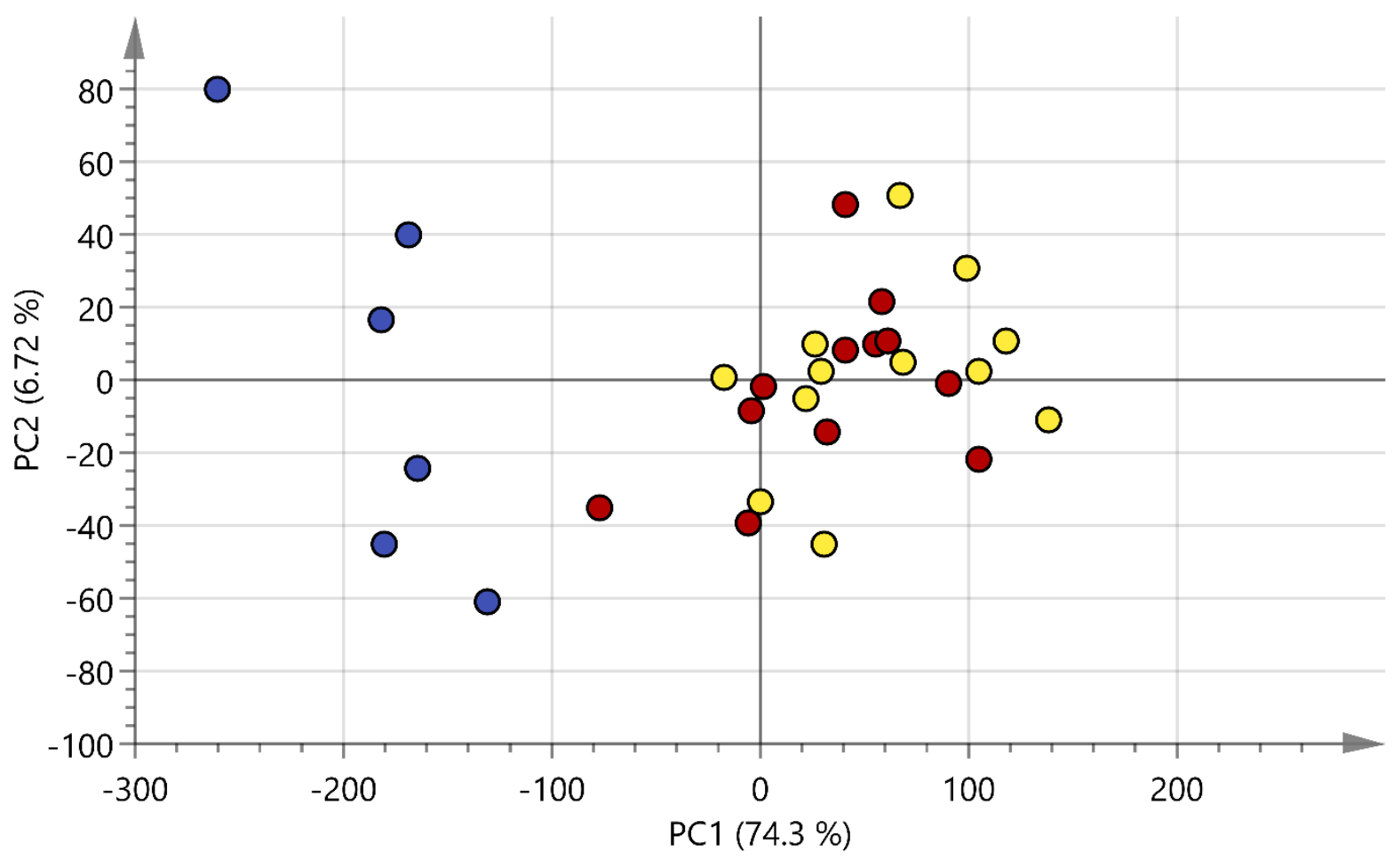




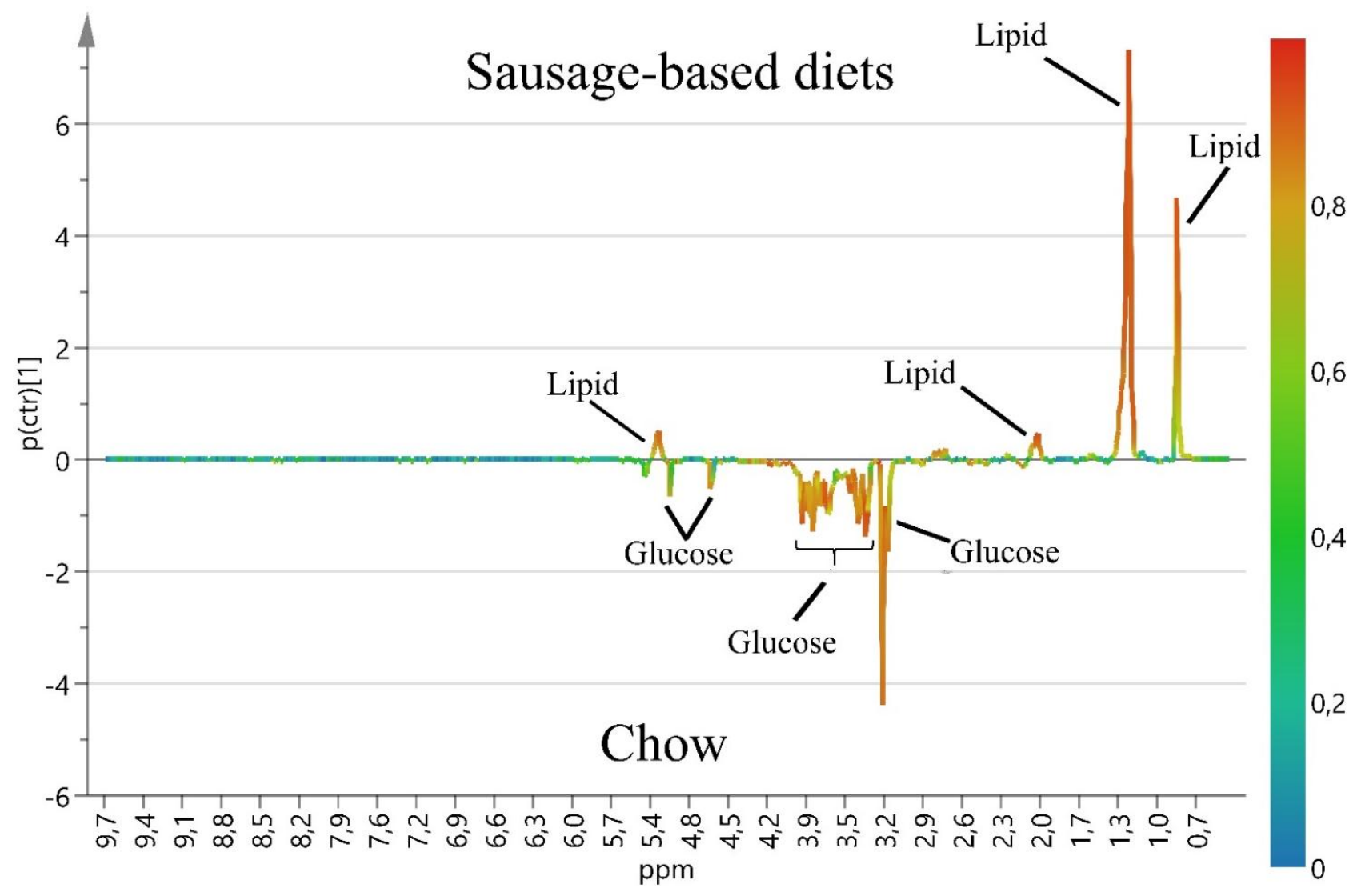




\section{Supplementary material}

\begin{tabular}{lccc}
\hline per $100 \mathrm{~g}$ & Control sausage & $\begin{array}{c}\text { Inulin-enriched } \\
\text { sausage }\end{array}$ & Chow \\
& 245.0 & 259.0 & 318.9 \\
\hline Energy (kcal) & 19.00 & 20.00 & 2.80 \\
\hline Fat (g) & 7.20 & 7.30 & 0.47 \\
\hline - Saturated & 8.30 & 8.40 & 0.63 \\
\hline - Monounsaturated & 2.60 & 3.10 & 1.69 \\
\hline - Polyunsaturated & 6.40 & 7.80 & 40.83 \\
\hline Carbohydrate (g) & 12.00 & 12.00 & 19.19 \\
\hline Protein (g) & 0.00 & 5.60 & 6.05 \\
\hline Dietary fiber* (g) & 2.50 & 2.50 & 0.54 \\
\hline NaCl (g) & & &
\end{tabular}

Table S1. Nutritional content of diets.

*Calculated values

\begin{tabular}{lcc}
\hline \multicolumn{1}{c}{ Ingredient $(\% \mathrm{w} / \mathrm{w})$} & Inulin-enriched sausage & Control sausage \\
\hline Inulin & 6.0 & - \\
\hline Salt (with 0.3nitrite) & 2.0 & 2.0 \\
\hline Spices & 2.0 & 2.0 \\
\hline AIN76 mineral mix: TD79055 & 2.0 & 2.0 \\
\hline AIN76 vitamin mix: CA40077 & 0.6 & 0.6 \\
\hline Choline bitartrate: CA30190 & 0.12 & 0.12 \\
\hline
\end{tabular}


Table S2. Ingredients added to emulsion of minced pork meat and pork back fat during manufacturing of the two sausage-based diets; pork sausages enriched with inulin and control pork sausages. 



\section{Concentration $[\mathrm{umol} / \mathrm{L}]$}

\begin{tabular}{|c|c|c|c|c|}
\hline \multirow[b]{2}{*}{ Rat ID } & ATNC & RSNO & FeNO & Other \\
\hline & \multicolumn{4}{|c|}{ Control sausage } \\
\hline 24 & 1.54 & 0.66 & 0.69 & 0.20 \\
\hline 6 & 1.21 & 0.33 & 0.89 & 0.00 \\
\hline 12 & 1.64 & 0.47 & 0.77 & 0.40 \\
\hline 4 & 1.78 & 0.50 & 0.94 & 0.34 \\
\hline 10 & 1.47 & 0.41 & 1.06 & 0.00 \\
\hline 2 & 1.45 & 0.32 & 0.78 & 0.34 \\
\hline 17 & 2.18 & 0.73 & 1.30 & 0.15 \\
\hline 25 & 3.88 & 1.06 & 2.61 & 0.21 \\
\hline 3 & 2.50 & 0.85 & 1.23 & 0.43 \\
\hline 29 & 2.11 & 0.44 & 1.32 & 0.35 \\
\hline 11 & 4.20 & 0.70 & 3.03 & 0.47 \\
\hline \multirow[t]{2}{*}{8} & 1.64 & 0.32 & 0.88 & 0.44 \\
\hline & \multicolumn{4}{|c|}{ Sausage + inulin } \\
\hline 26 & 1.18 & 0.10 & 0.92 & 0.17 \\
\hline 9 & 0.96 & 0.24 & 0.71 & 0.00 \\
\hline 30 & 1.38 & 0.50 & 0.88 & 0.00 \\
\hline 16 & 1.84 & 0.69 & 0.86 & 0.29 \\
\hline 23 & 0.70 & 0.14 & 0.56 & 0.00 \\
\hline 7 & 2.38 & 0.76 & 1.05 & 0.57 \\
\hline 18 & 0.95 & 0.24 & 0.27 & 0.44 \\
\hline 14 & 1.01 & 0.25 & 0.72 & 0.04 \\
\hline 28 & 1.27 & 0.51 & 0.73 & 0.03 \\
\hline 27 & 1.65 & 0.47 & 0.80 & 0.38 \\
\hline 19 & 1.30 & 0.42 & 0.88 & 0.00 \\
\hline 5 & 2.08 & 0.61 & 1.05 & 0.41 \\
\hline
\end{tabular}

Table S3. Concentration of fecal nitroso compounds after 4 weeks of intervention in rats. ATNC, apparent total N-nitroso compounds; RSNO, nitrosothiols; FeNO, nitrosyl iron compounds; other, remaining unspecified nitroso compounds. For the chow diet group, all nitroso compounds analyzed were below the detection limit. 


\begin{tabular}{ccccc}
\hline & Chow & Sausage + & Control & p- \\
& & inulin & sausage & value \\
\hline MDA (nmol/g DM) & $73.9 \pm 4.7^{\mathrm{a}}$ & $91.0 \pm 0.8^{\mathrm{b}}$ & $76.5 \pm 2.4^{\mathrm{a}}$ & 0.016 \\
\hline 4-HNE (ng/g DM) & $72.3 \pm 8.4^{\mathrm{a}}$ & $9.7 \pm 2.1^{\mathrm{b}}$ & $8.8 \pm 1.9^{\mathrm{b}}$ & $<0.001$ \\
\hline HEX (ng/g DM) & $573.7 \pm 29.5^{\mathrm{a}}$ & $17.0 \pm 0.6^{\mathrm{b}}$ & $20.1 \pm 4.9^{\mathrm{b}}$ & $<0.001$ \\
\hline
\end{tabular}

Table S4. Lipid oxidation of experimental diets expressed per gram dry matter, mean \pm SEM ( $n=3$ for each diet group). MDA, malondialdehyde; 4-HNE, 4-hydroxy-2-nonenal; HEX, hexanal; DM, dry matter. 


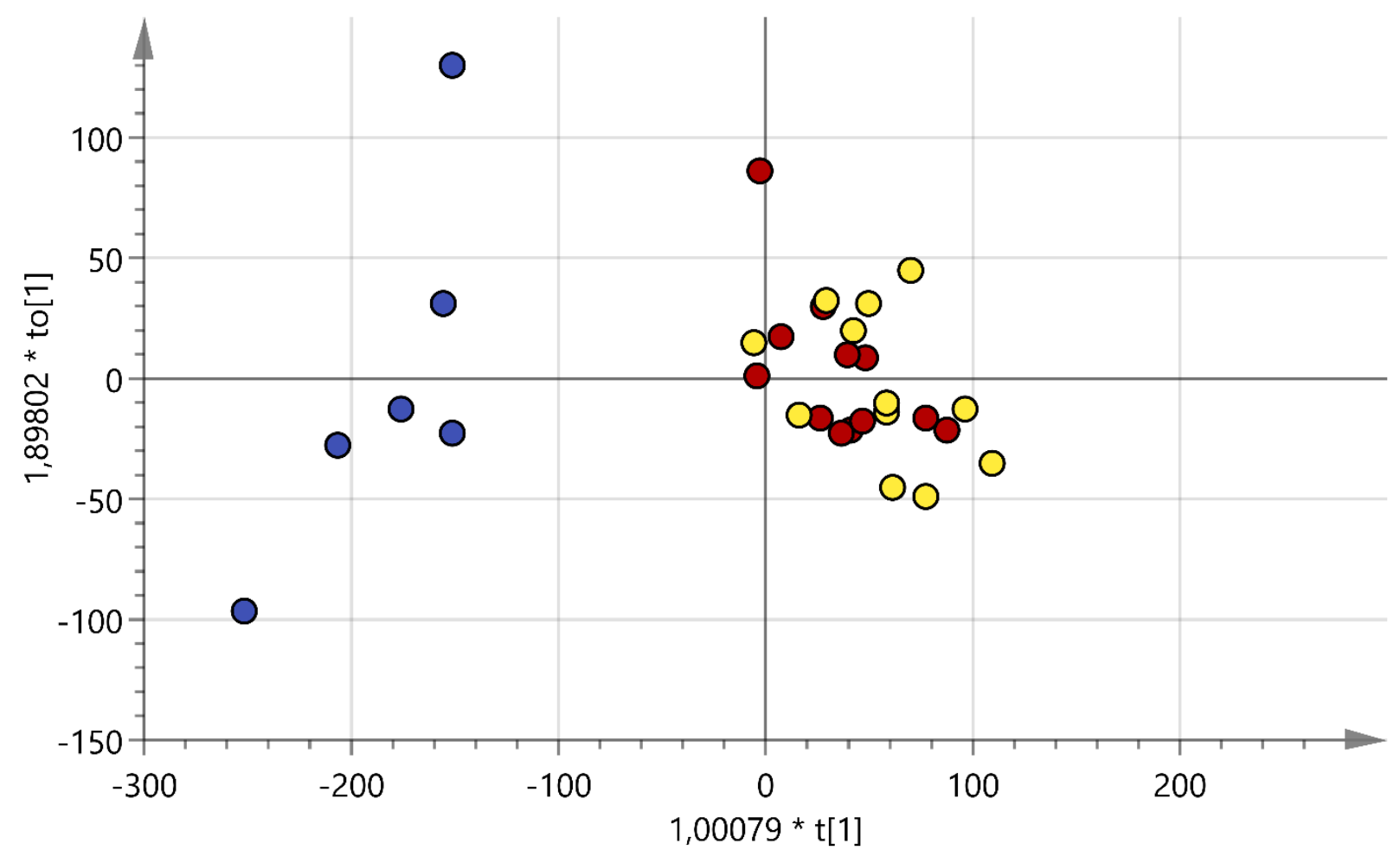

Figure S1. OPLS-DA scores plot of metabolite profiles obtained for liver samples from rats fed standard chow diet (blue), inulin-enriched sausage (yellow) or control sausage (red), $Q^{2}=0.79$. 